Department of Infectious and Tropical Diseases, London School of Hygiene and Tropical Medicine, London WC1E 7HT

${ }^{2}$ Department of Epidemiology and Public Health, London School of Hygiene and Tropical Medicine

${ }^{3}$ World Bank, Washington, DC, USA

Correspondence to: T Clasen thomas.clasen@lshtm.ac.uk

doi: 10.1136/bmj.39118.489931.BE

\title{
Interventions to improve water quality for preventing diarrhoea: systematic review and meta-analysis
}

\author{
Thomas Clasen, lecturer, ${ }^{1}$ Wolf-Peter Schmidt, clinical research fellow, ${ }^{1}$ Tamer Rabie, public health \\ specialist, ${ }^{3}$ lan Roberts, professor of epidemiology, ${ }^{2}$ Sandy Cairncross, professor of environmental health
}

\section{ABSTRACT}

Objective To assess the effectiveness of interventions to improve the microbial quality of drinking water for preventing diarrhoea.

Design Systematic review.

Data sources Cochrane Infectious Diseases Group's trials register, CENTRAL, Medline, Embase, LILACS; hand searching; and correspondence with experts and relevant organisations.

Study selection Randomised and quasirandomised controlled trials of interventions to improve the microbial quality of drinking water for preventing diarrhoea in adults and in children in settings with endemic disease.

Data extraction Allocation concealment, blinding, losses to follow-up, type of intervention, outcome measures, and measures of effect. Pooled effect estimates were calculated within the appropriate subgroups.

Data synthesis 33 reports from 21 countries documenting 42 comparisons were included. Variations in design, setting, and type and point of intervention, and variations in defining, assessing, calculating, and reporting outcomes limited the comparability of study results and pooling of results by meta-analysis. In general, interventions to improve the microbial quality of drinking water are effective in preventing diarrhoea. Effectiveness did not depend on the presence of improved water supplies or sanitation in the study setting and was not enhanced by combining the intervention with instructions on basic hygiene, a water storage vessel, or improved sanitation or water supplies-other common environmental interventions intended to prevent diarrhoea.

Conclusion Interventions to improve water quality are generally effective for preventing diarrhoea in all ages and in under $5 \mathrm{~s}$. Significant heterogeneity among the trials suggests that the level of effectiveness may depend on a variety of conditions that research to date cannot fully explain.

\section{INTRODUCTION}

Diarrhoeal diseases kill an estimated 1.8 million people each year. ${ }^{1}$ In developing countries diarrhoea accounts for $17 \%$ of deaths among under $5 \mathrm{~s}^{2}$ For the 1.1 billion people who lack access to improved water supplies, ${ }^{3}$ and many more with contaminated water, diarrhoeal disease is highly endemic. Nevertheless, the effectiveness of interventions aimed at improving the quality of drinking water has been questioned..$^{4-6}$ Because people can become infected with organisms that cause diarrhoea through multiple pathways, water quality alone may not interrupt transmission. ${ }^{7}$ Even in developed countries with improved water supplies, diarrhoea is often endemic. ${ }^{89}$

Previous reviews of environmental interventions to prevent diarrhoeal disease reported a $15 \%$ to $17 \%$ median reduction in diarrhoea from water quality interventions. $^{1011}$ All included studies concerned improvements at the water source or collection point (protected wells, boreholes, communal tap stands) and none at the household level or other points of use. Recent studies have drawn attention to the potential role of interventions at the household level to reduce the occurrence of diarrhoea. ${ }^{12-14}$ Such interventions might minimise recontamination in the home, a well known cause of water quality degradation. ${ }^{15}$

We report updated results of a systematic review undertaken with the Cochrane Collaboration on the effectiveness of interventions to improve the microbial quality of drinking water for preventing endemic diarrhoea. ${ }^{16}$

\section{METHODS}

We searched for all randomised and quasirandomised controlled trials of interventions to improve water quality for the prevention of diarrhoeal disease, regardless of language, publication status, or date of study. Participants were adults or children in settings with endemic diarrhoeal disease - that is, regularly present in the population. We excluded interventions in response to epidemic diarrhoea. Interventions included any measure to improve the microbial quality of drinking water. The primary outcome was diarrhoea related morbidity.

We searched the specialised register of the Cochrane Infectious Diseases Group, CENTRAL, Medline, Embase, and LILACS to December 2005. We hand searched conference proceedings, contacted researchers and organisations working in the specialty, and checked the references of identified studies. Two reviewers independently examined the electronic records for potentially eligible studies and examined 
the full text of potentially eligible reports. Disagreements were resolved by a third reviewer.

\section{Data extraction: measure of effect and methodological quality}

Two reviewers independently extracted data. Measures of effects reported were risk ratios, rate ratios, odds ratios, and longitudinal prevalence ratios (number of days or weeks with diarrhoea divided by number of days or weeks under observation in a person). As many of the trials were cluster randomised and had taken clustering into account in the data analysis (sometimes adjusting for covariates) we could not use the reported data to recalculate a common measure and yet preserve such adjustments. We therefore present the results separately according to the reported measures of effect.

For randomised controlled trials we extracted data on the methods used to generate the allocation sequence, allocation concealment, blinding of outcome assessment, and inclusion or losses to follow-up on the basis of criteria developed by Juni. ${ }^{17}$ For quasirandomised controlled trials we assessed the comparability of intervention and control groups at baseline for water quality, diarrhoeal morbidity, age, socioeconomic status, access to water, hygiene practices, and sanitation facilities, and whether data collection for intervention and control groups was contemporaneous.

\section{Data analysis and synthesis}

We used a random effects inverse variance method on the $\log$ scale to calculate pooled estimates ${ }^{18}$ and displayed the results graphically using RevMan 4.2. Heterogeneity was examined both visually by examining forest plots and statistically by using the $\chi^{2}$ test with a $10 \%$ level of statistical significance ${ }^{19}$ and the $\mathrm{I}^{2}$ test for consistency. ${ }^{20}$ Factors specified a priori in the study protocol as potential explanations for observed heterogeneity were age (all ages $v$ under $5 \mathrm{~s}$ ), point of intervention (water source $v$ household), type of intervention (water quality only $v$ compound interventions: including hygiene messages, improved sanitation, improved supply), compliance $(<50 \% \quad v \geq 50 \%)$, and effectiveness under various conditions for water supply, sanitation, and water access (using global assessment definitions from the joint World Health Organization and United Nations Children's Fund). ${ }^{3}$ We included all intervention arms in the meta-analysis even for trials in which two or more intervention arms were compared against one control, but identify this as a potential methodological flaw in the pooled estimates of effect.

\section{RESULTS}

The combined search strategies identified 976 potentially relevant studies of interventions to improve water quality for preventing diarrhoea. The full text of 68 potentially eligible reports was obtained for further assessment after screening of titles and abstracts. Of these 68 reports, 33 with 42 controlled comparisons met the inclusion criteria (fig 1). ${ }^{\text {1-w33 }}$ The meta-analysis includes three new studies not in the original review. ${ }^{\text {w6 w9 w29 }}$ Six studies included two or more intervention arms.

The 33 studies (22 randomised controlled trials, 11 quasirandomised controlled trials) included about 55650 participants (table 1). Eighteen studies presented results for participants of all ages, 10 included only under $5 \mathrm{~s}$ or a subgroup thereof, and the remainder reported on both age groups. In most trials the household was the unit of randomisation, although some randomised neighbourhoods, clusters of households, or villages. Trials of interventions at the water source (mainly the quasirandomised controlled trials) were generally longer (median 36 months, range 12 to 60 months) than those of household interventions (median 7 months, range 9.5 weeks to 12 months). All but two trials from the United States ${ }^{\text {w8 }}{ }^{\text {w9 }}$ were carried out in developing countries. Two trials took place in urban settings, two in peri-urban settings, three in urban informal or squatter settlements, two in refugee camps, one in multiple settings, and the others in rural settings.

\section{Interventions}

The interventions to improve drinking water quality were undertaken at the level of either the water source (seven trials) or the household (35 trials). Water source interventions included protected wells, bore holes, or distribution to public tap stands; none included piped in (reticulated) household connections. Household interventions comprised improved water storage (one trial) or one of four approaches for treating water in the home: chlorination (16 trials), solar disinfection (three trials), filtration (eight trials), or combined flocculation and disinfection (seven trials). Apart from solar disinfection and flocculation-disinfection using a water purifying product (PUR sachet; Procter and Gamble), there were potentially important differences in the types of interventions. For example, filtration interventions varied by filter medium and pore size, and chlorination varied by chlorine source, dose, and contact time.

Improvements in water quality were often accompanied by other environmental interventions intended to

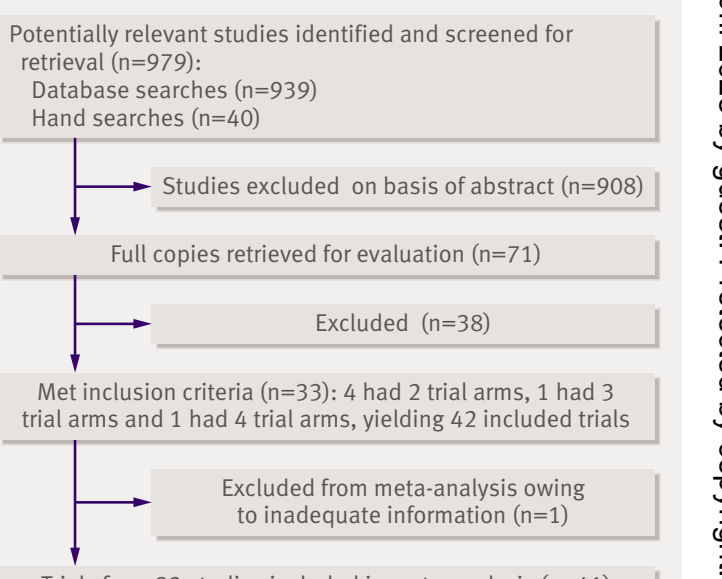

Trials from 32 studies included in meta-analysis $(n=41)$

Fig 1 | Flow chart of search 
Table 1 | Details of included studies on interventions to improve microbial quality of drinking water for preventing diarrhoea

\begin{tabular}{|c|c|c|c|}
\hline Study & Design and setting (duration) & No of participants (age) & Intervention \\
\hline Alam $1989^{\text {w1 }}$ & $\begin{array}{l}\text { QRCT among five political subunits of a village in rural } \\
\text { Bangladesh (3 years) }\end{array}$ & 623 (6-23 months) & Improved water supply and hygiene education \\
\hline Austin $1993^{\mathrm{w} 2}$ & $\begin{array}{l}\text { RCT among } 22 \text { rural villages ( } 11 \text { intervention, } 11 \text { control) in } \\
\text { Gambia; unit of randomisation was village ( } 20 \text { weeks) }\end{array}$ & $\begin{array}{l}\text { Arm 1, } 287 \text { ( } 25-60 \text { months); } \\
\text { arm 2, } 144 \text { (6-24 months) }\end{array}$ & Sodium hypochlorite solution used at household level \\
\hline Aziz $1990^{\text {w3 }}$ & QRCT among two villages in rural Bangladesh (3 years) & About 9600 (all ages) & Improved water supply, sanitation, and hygiene education \\
\hline Chiller $2005^{\mathrm{w} 4}$ & $\begin{array}{l}\text { RCT in } 42 \text { neighbourhood clusters in } 12 \text { rural villages in } \\
\text { Guatemala (13 weeks) }\end{array}$ & 3401 (all ages) & $\begin{array}{l}\text { Flocculant-disinfectant sachets used at household level and } \\
\text { hygiene education }\end{array}$ \\
\hline Clasen $2004^{\mathrm{w} 5}$ & $\mathrm{RCT}$ in rural Bolivian community (6 months) & 280 (all ages) & \multirow{3}{*}{$\begin{array}{l}\text { Household gravity water filter system using imported ceramic filter } \\
\text { elements }\end{array}$} \\
\hline Clasen $2006^{\mathrm{w} 6}$ & RCT in rural Bolivian community (5 months) & 324 (all ages) & \\
\hline Clasen $2005^{\mathrm{w} 7}$ & $\begin{array}{l}\text { RCT among three villages in conflict affected rural Colombia } \\
\text { (6 months) }\end{array}$ & 680 (all ages) & \\
\hline Colford $2002^{\text {w8 }}$ & Triple blinded RCT in urban USA (4 months) & 236 ( $\geq 12$ years) & Household reverse osmosis filters \\
\hline Colford $2005^{\mathrm{w} 9}$ & Crossover triple blinded RCT in urban USA (12 months) & 1296 (all ages) & Household filtration and ultraviolet unit \\
\hline Conroy $1996^{\text {w10 }}$ & RCT among Maasai in rural Kenya (12 weeks) & 206 (5-16 years) & Solar disinfection in plastic bottles at household level \\
\hline Conroy $1999^{\text {w11 }}$ & RCT among Maasai in rural Kenya (1 year) & 349 (under 6s) & Solar disinfection in plastic bottles at household level \\
\hline Crump $2005^{\mathrm{w} 12}$ & $\begin{array}{l}\text { Cluster randomised, RCT among rural } 49 \text { villages in western } \\
\text { Kenya ( } 20 \text { weeks) }\end{array}$ & 6650 (all ages) & $\begin{array}{l}\text { Intervention 1, hygiene education and sodium hypochlorite used at } \\
\text { household level; intervention 2, hygiene and flocculant- } \\
\text { disinfectant sachets used at household level }\end{array}$ \\
\hline Doocy $2006^{\text {w13 }}$ & RCT in Liberian camp for displaced people (12 weeks) & 2191 (all ages) & $\begin{array}{l}\text { Flocculant-disinfectant sachets used at household level and water } \\
\text { storage vessel }\end{array}$ \\
\hline Du Preez $2004^{\mathrm{w} 14}$ & RCT in rural South Africa and Zimbabwe (6 months) & 115 (under 5s) & Household commercial ceramic filter using imported components \\
\hline Garrett $2004^{\mathrm{w} 15}$ & QRCT in rural Kenya (not stated) & 960 (under 5s) & $\begin{array}{l}\text { Household chlorination using sodium hypochlorite solution; } \\
\text { improved water supply; sanitation; hygiene education; and } \\
\text { improved storage }\end{array}$ \\
\hline Gasana $2002^{\text {w16 }}$ & QRCT in rural Rwanda (1 year) & 150 (under 5s) & $\begin{array}{l}\text { Improved source (pipes to stand post, sedimentation tank, ceramic } \\
\text { filter, storage tank, and communal tap) }\end{array}$ \\
\hline Handzel $1998^{\mathrm{w} 17}$ & RCT in informal settlement in urban Bangladesh (8 months) & 447 (3 to 60 months) & $\begin{array}{l}\text { Household chlorination using sodium hypochlorite solution, } \\
\text { special storage vessel, and hygiene instruction }\end{array}$ \\
\hline Jensen $2003^{\text {w18 }}$ & QRCT among two villages in Pakistan (6 months) & 226 (under 5s) & $\begin{array}{l}\text { Village level chlorination of water supply using calcium } \\
\text { hypochlorite }\end{array}$ \\
\hline Kirchhoff $1985^{\mathrm{w} 19}$ & Blinded crossover RCT in rural Brazil (18 weeks) & $\begin{array}{l}112 \text { people from } 20 \text { families } \\
\text { (all ages) }\end{array}$ & Household level chlorination with sodium hypochlorite \\
\hline \multirow[t]{2}{*}{ Luby $2004^{\mathrm{w} 20}$} & \multirow{2}{*}{$\begin{array}{l}\text { QRCT among three neighbourhoods in squatter settlements in } \\
\text { Karachi, Pakistan (6 months) }\end{array}$} & \multirow[t]{2}{*}{2365 ( $(15$ years) } & Bleach and regular storage vessel \\
\hline & & & Bleach and insulated storage vessel \\
\hline \multirow[t]{3}{*}{ Luby $2006^{\text {w21 }}$} & \multirow{3}{*}{$\begin{array}{l}\text { RCT among } 47 \text { squatter settlements in Karachi, Pakistan } \\
\text { (8 months) }\end{array}$} & \multirow[t]{3}{*}{8949 (all ages) } & Dilute bleach and storage vessel \\
\hline & & & Flocculant-disinfectant and soap \\
\hline & & & Flocculant-disinfectant and storage vessel \\
\hline Lule $2005^{\text {w22 }}$ & $\begin{array}{l}\text { RCT among households in rural Uganda, at least one person HIV } \\
\text { positive ( } 5 \text { months) }\end{array}$ & 2201 (all ages) & $\begin{array}{l}\text { Household level chlorination using sodium hypochlorite; hygiene } \\
\text { education was provided to both intervention and control groups }\end{array}$ \\
\hline Mahfouz $1995^{\text {w23 }}$ & QRCT among nine villages in rural Saudi Arabia (6 months) & 311 (under 5s) & Household level chlorination using calcium hypochlorite \\
\hline Messou $1997^{\text {w24 }}$ & $\begin{array}{l}\text { QRCT among four villages in rural Ivory Coast; two underwent } \\
\text { intervention, two were controls ( } 5 \text { years) }\end{array}$ & $\begin{array}{l}985-1260 \text {, depending on } \\
\text { study year (under } 5 \mathrm{~s} \text { ) }\end{array}$ & $\begin{array}{l}\text { Improved water supply, sanitation, hygiene education, and oral } \\
\text { rehydration therapy for those with diarrhoea }\end{array}$ \\
\hline Quick 1999 ${ }^{\text {w25 }}$ & RCT among two peri-urban communities in Bolivia (5 months) & 791 (all ages) & $\begin{array}{l}\text { Household level chlorination, storage vessel, and hygiene } \\
\text { education }\end{array}$ \\
\hline Quick $2002^{\mathrm{w} 26}$ & QRCT in two peri-urban communities in Zambia (3 months) & 1584 (all ages) & $\begin{array}{l}\text { Household level chlorination, storage vessel, and hygiene } \\
\text { education }\end{array}$ \\
\hline Reller $2003^{\mathrm{w} 27}$ & RCT among 12 villages in rural Guatemala (12 months) & 2982 (all ages) & $\begin{array}{l}\text { Intervention 1, flocculant-disinfectant; intervention 2, bleach only; } \\
\text { intervention 3, bleach and storage vessel; intervention 4, } \\
\text { flocculant-disinfectant and storage vessel }\end{array}$ \\
\hline Roberts $2001^{\text {w28 }}$ & RCT in a Malawi refugee camp (4 months) & 1160 (all ages) & $\begin{array}{l}\text { Improved storage: bucket with spout and narrow opening to limit } \\
\text { hand entry }\end{array}$ \\
\hline Rose $2005^{\text {w29 }}$ & RCT in urban slum in south India (6 months) & 200 (under 5s) & Solar disinfection in plastic bottles at household level \\
\hline Semenza $1998^{\text {w30 }}$ & $\begin{array}{l}\text { RCT in urban Uzbekistan among } 240 \text { households, half with and } \\
\text { half without access to piped water ( } 9.5 \text { weeks) }\end{array}$ & 1583 (all ages) & $\begin{array}{l}\text { Household level chlorination, storage vessel, and hygiene } \\
\text { education }\end{array}$ \\
\hline Turon $1982^{\mathrm{w} 31}$ & QRCT in two small villages in Guatemala (12 months) & 2103 (all ages) & $\begin{array}{l}\text { Source protection (spring), chlorination facilities, "adequate } \\
\text { storage," and water mains with faucets to yards }\end{array}$ \\
\hline $\begin{array}{l}\text { Universidad Rafael } \\
\text { Landivar } 1995^{\text {w32 }}\end{array}$ & $\begin{array}{l}\text { Study from three demographic regions of Guatemala } \\
\text { (12 months) }\end{array}$ & 1120 (under 5s) & $\begin{array}{l}\text { Intervention } 1 \text {, locally fabricated ceramic filters; intervention } 2 \text {, } \\
\text { locally fabricated ceramic filters and hygiene education }\end{array}$ \\
\hline Xiao $1997^{\text {w33 }}$ & QRCT among two villages in rural China (3 years) & 4649 (all ages) & Improved water supply, sanitation, and hygiene education \\
\hline
\end{tabular}


prevent faecal-oral transmission, including improved sanitation and water supplies, improved water storage in the home, and instruction on basic hygiene regarding contaminated water and diarrhoeal disease (table 1). One study included the introduction of oral rehydration therapy. ${ }^{\mathrm{w} 24}$ However, 14 trials consisted solely of water quality interventions, although ceramic filters and solar disinfection interventions may also improve storage.

\section{Compliance}

Compliance (consumption of improved quality water) was not assessed directly. Trials of interventions at the water source tended to assume compliance on the basis that the primary water supply had been improved. Some trials of household water treatment undertook indirect assessments of compliance by measuring residual chlorine levels in stored water, ${ }^{\text {w2 }}$ w4 w12 w13 w15 w17 w23 w25-w27 w30 comparing microbial water quality of intervention and control households, ${ }^{\text {w4 w5-w6 w12 w19 }}$ carrying out periodic or post-study surveys, ${ }^{\text {w4 w27 } 29}$ or counting the amount of intervention product used. ${ }^{\text {w27 }}$ Seven trials did not report compliance. ${ }^{\mathrm{w} 1 \mathrm{w} 11 \mathrm{w} 20 \mathrm{w} 22 \mathrm{w} 31 \mathrm{w} 33}$

Even when efforts were made to document compliance, investigators acknowledged that it was not possible to determine the extent to which participants in the intervention group consumed treated water or avoided consuming untreated water.

\section{Outcome measures and effect estimates}

Twenty one trials used the WHO definition of diarrhoea (three or more loose stools in the previous 24 hours); most others used local terms or mothers' definitions. All were based on self report. In most trials participants were visited on a periodic basis, either weekly (14 trials), fortnightly (five trials), or more infrequently (five trials), and were asked to recall episodes of diarrhoea during a

Table 2 | Summary of pooled estimates (random effects) for studies reporting rate ratios, risk ratios, longitudinal prevalence ratios, and odds ratios for all studies (source based and household based), by point of intervention (source or household), and by type of household water treatment (chlorination, filtration, solar disinfection, and flocculation-disinfection)

\begin{tabular}{|c|c|c|c|c|c|c|c|c|}
\hline \multirow[b]{2}{*}{$\begin{array}{l}\text { Measure of effect and } \\
\text { intervention }\end{array}$} & \multicolumn{4}{|c|}{ All ages } & \multicolumn{4}{|c|}{ Under 5s } \\
\hline & $\begin{array}{l}\text { No of } \\
\text { trials }\end{array}$ & $\begin{array}{l}\text { Pooled estimate* } \\
(95 \% \mathrm{Cl})\end{array}$ & $\begin{array}{l}\text { Probabil- } \\
\text { ity of } \\
\text { hetero- } \\
\text { geneity† }\end{array}$ & $\begin{array}{c}\text { Consis- } \\
\text { tency } \neq \\
(\%)\end{array}$ & $\begin{array}{l}\text { No of } \\
\text { tTrials }\end{array}$ & Pooled estimate* $(95 \% \mathrm{Cl})$ & $\begin{array}{c}\text { Probability } \\
\text { of } \\
\text { heteroge- } \\
\text { neity† }\end{array}$ & $\begin{array}{l}\text { Con- } \\
\text { sisten- } \\
\text { cy (\%) }\end{array}$ \\
\hline \multicolumn{9}{|l|}{ Rate ratios } \\
\hline All & 12 & 0.75 (0.65 to 0.87$) \S$ & $<0.0001$ & 92.3 & 8 & 0.81 (0.69 to 0.95$)$ & 0.0001 & 92.2 \\
\hline Source based & 4 & 0.87 (0.74 to 1.02$)$ & 0.0002 & 85.1 & 3 & 0.93 (0.82 to 1.05$)$ & 0.17 & 44.3 \\
\hline Household based: & 8 & $0.62(0.47$ to 0.82$) \S$ & 0.0001 & 88.9 & 5 & 0.70 (0.54 to 0.89$)$ & 0.0001 & 86.8 \\
\hline Chlorination & 4 & 0.61 (0.46 to 0.81$) \S$ & 0.01 & 72.8 & 2 & 0.53 (0.23 to 1.23$)$ & 0.002 & 89.4 \\
\hline Filtration & 3 & $0.56(0.25$ to 1.27$)$ & 0.003 & 83.2 & 2 & $0.51(0.11$ to 2.37$)$ & 0.004 & 88.1 \\
\hline Solar disinfection & 1 & 0.64 (0.41 to 1.00$)$ & NA & NA & 1 & 0.64 (0.41 to 1.00$)$ & NA & NA \\
\hline \multicolumn{9}{|l|}{ Risk ratios } \\
\hline All & 8 & 0.50 (0.41 to 0.61$) \S$ & 0.0001 & 85.7 & 6 & $0.61(0.48$ to 0.77$) \S$ & 0.13 & 40.8 \\
\hline Source based & 1 & 0.45 (0.43 to 0.47$)$ & NA & NA & 0 & NA & NA & NA \\
\hline Household based: & 7 & $0.49(0.36$ to 0.65$) \S$ & 0.002 & 71.8 & 6 & $0.61(0.48$ to 0.77$) \S$ & 0.13 & 40.8 \\
\hline Chlorination & 4 & $0.41(0.26$ to 0.65$)$ & 0.003 & 78.4 & 3 & $0.60(0.41$ to 0.87$)$ & 0.06 & 64.7 \\
\hline Filtration & 2 & $0.41(0.21$ to 0.79$) \S$ & 0.66 & 0 & 2 & $0.41(0.21$ to 0.79$) \S$ & 0.66 & 0 \\
\hline Improved storage & 1 & $0.79(0.61$ to 1.03$)$ & NA & NA & 1 & 0.69 (0.47 to 1.01$)$ & NA & NA \\
\hline \multicolumn{9}{|c|}{ Longitudinal prevalence ratios } \\
\hline All & 11 & $0.56(0.27$ to 1.16$) \S$ & 0.0001 & 98.8 & 11 & $0.61(0.29$ to 1.26$) \S$ & 0.0001 & 99.0 \\
\hline Source based & 1 & $0.56(0.37$ to 0.84$)$ & NA & NA & 1 & 0.63 (0.49 to 0.81$)$ & NA & NA \\
\hline Household based: & 10 & $0.56(0.25$ to 1.23$) \S$ & 0.0001 & 98.9 & 10 & $0.60(0.27$ to 1.36$) \S$ & 0.0001 & 99.1 \\
\hline Chlorination & 5 & $0.82(0.60$ to 1.11$) \S$ & 0.04 & 60.4 & 5 & $0.91(0.82$ to 1.02$) \S$ & 0.75 & 0 \\
\hline $\begin{array}{l}\text { Flocculation- } \\
\text { disinfection }\end{array}$ & 5 & $0.40(0.14,1.16) \S$ & 0.0001 & 98.9 & 5 & $0.42(0.13$ to 1.37$) \S$ & 0.0001 & 99.2 \\
\hline \multicolumn{9}{|l|}{ Odds ratios } \\
\hline All & 10 & 0.65 (0.56 to 0.76$) \S$ & 0.0005 & 69.7 & 7 & 0.65 (0.46 to 0.91$) \S$ & 0.004 & 69.0 \\
\hline Household based: & 10 & 0.65 (0.56 to 0.76$) \S$ & 0.0005 & 69.7 & 7 & $0.65(0.46$ to 0.91$) \S$ & 0.004 & 69.0 \\
\hline Chlorination & 3 & 0.77 (0.58 to 1.02$) \S$ & 0.08 & 59.5 & 2 & $0.90(0.65$ to 1.25$) \S$ & 0.74 & 0 \\
\hline Filtration & 3 & 0.37 (0.27 to 0.49$)$ & 0.49 & 0 & 3 & $0.37(0.22$ to 0.62$)$ & 0.23 & 32.5 \\
\hline Solar disinfection & 2 & $0.69(0.63$ to 0.74$)$ & 0.76 & 0 & 0 & NA & NA & NA \\
\hline $\begin{array}{l}\text { Flocculation- } \\
\text { disinfection }\end{array}$ & 2 & $0.77(0.65$ to 0.90$) \S$ & 0.70 & 0 & 2 & $0.86(0.57$ to 01.29$) \S$ & 0.06 & 72.1 \\
\hline
\end{tabular}

NA=not applicable.

*For single studies, estimate is from that study only.

$+x^{2}$

§Includes studies with multiple intervention arms compared with a single control so that statistical significance of these analyses must be interpreted with caution. 
previous period, usually seven days (18 trials) to 14 days (six trials). In some trials participants were asked to keep records of days with diarrhoea.

Effect estimates included rate ratios (12 trials), risk ratios (eight trials), longitudinal prevalence ratios (11 trials), and odds ratios (10 trials; table 2). One trial did not provide enough information to calculate the actual measure of effect and was excluded from the metaanalysis. ${ }^{\text {w31 }}$ Most studies adjusted for covariates. However, none of the source based interventions and four of the household based trials ${ }^{\text {w2 }}$ w19 w23 w32 did not report adjusting for clustering and may thus receive excess weight in meta-analysis due to artificial precision.

\section{Effectiveness}

Figure 2 present the forest plots for studies reporting effect estimates for all ages and for under $5 \mathrm{~s}$. Most trials recorded notable reductions in diarrhoea; none found the interventions to be associated with a statistically significant increase in diarrhoea related morbidity. The evidence from the pooled estimates of effect for all trials by each measure of effect suggests that interventions to improve the microbial quality of drinking water are effective in reducing the occurrence of diarrhoea both for all participants and for under $5 \mathrm{~s}$ (table 2). Pooled estimates were, however, characterised by considerable heterogeneity (table 2). A subgroup analysis was carried out on the criteria specified in the protocol to attempt to explain such heterogeneity.

\section{Exploring heterogeneity}

\section{Water source versus household interventions}

Table 2 shows the pooled estimates of interventions at the water source level and at the household level. Although individual trials of source based interventions reported the intervention to be effective, the pooled estimate for trials using rate ratios fell short of statistical significance, both among four trials reporting data for all ages $(0.87,95 \%$ confidence interval 0.74 to 1.02$)$ and three trials reporting on under $5 \mathrm{~s}(0.93$, 0.82 to 1.05$)$. The two studies on source based interventions reporting the highest level of effectiveness could not be pooled because they used different measures of effect. ${ }^{\text {w24 w33 }}$ Moreover, the small number of clusters and the failure to take clustering into account in the analysis must raise doubts about the validity of such estimates. Household interventions, on the other hand, significantly reduced diarrhoea episodes among people of all ages and among under $5 \mathrm{~s}$, as measured with rate ratios, risk ratios, and odds ratios, but these pooled estimates were still heterogeneous. The pooled longitudinal prevalence ratio for household interventions was statistically significant when a possible outlier $^{\text {w13 }}$ was excluded from the analysis for all age groups $(0.70,0.56$ to 0.88 ; nine trials) and for under $5 \mathrm{~s}(0.76,0.66$ to 0.88 ; nine trials $)$.

\section{Type of household intervention}

Table 2 also shows the pooled estimates of effect by type of household intervention. Although such subgrouping reduces heterogeneity among certain types of household interventions other pooled estimates were still characterised by considerable heterogeneity. Household chlorination was associated with a statistically significant reduction in diarrhoea among all age groups when measured using rate ratios and risk ratios, and in under $5 \mathrm{~s}$ when using risk ratios. No statistically significant advantage was found for people of all ages when measured using longitudinal prevalence ratios or for under $5 \mathrm{~s}$ when measured using rate ratios, longitudinal prevalence ratios, or odds ratios. Household filters were associated with a statistically significant and homogeneous reduction in diarrhoea among all ages and in under $5 \mathrm{~s}$ for trials measuring risk ratios and odds ratios, but not among trials measuring rate ratios. Excluding the two studies carried out in the United States in settings with high ambient water quality, ${ }^{\text {w8 }}{ }^{\mathrm{w} 9}$ however, resulted in a single study reporting a statistically significant rate ratio in favour of the intervention $(0.21,95 \%$ confidence interval 0.07 to 0.61 ). Solar disinfection was associated with a reduction in diarrhoea among all ages in both trials measuring odds ratios. A single study that measured the effectiveness of the intervention among under $5 \mathrm{~s}$ reported a rate ratio of 0.64 (0.41 to 1.00). For household based flocculation-disinfection, pooled estimates from the five trials reporting longitudinal prevalence ratios found no statistically significant difference in the number of diarrhoea episodes compared with the control, either for people of all ages or for under $5 \mathrm{~s}$. However, excluding one trial ${ }^{\mathrm{w} 13}$ that found a substantial protective effect but which has been identified as a possible outlier rendered the pooled estimate statistically significant in favour of the intervention, both for all ages $(0.60,0.43$ to 0.83$)$ and for under $5 \mathrm{~s}(0.66,0.43$ to 0.76$)$. The two trials using odds ratios reported a statistically significant reduction in diarrhoea episodes for all ages from household based flocculation-disinfection but not for under $5 \mathrm{~s}$. The one trial that involved improved storage found a protective but, lacking power, not statistically significant difference in diarrhoea episodes, measured with risk ratios, for people of all ages $(0.79,0.61$ to $1.03)$ and for under $5 \mathrm{~s}(0.69,0.47$ to 1.01$) .{ }^{\text {w28 }}$

\section{Compliance}

Among trials reporting odds ratios, the pooled estimate of effect was substantially higher in settings where compliance with the intervention was higher ( $\geq 50 \%$ compliance (four trials), odds ratio $0.39,95 \%$ confidence interval 0.39 to $0.51 v<50 \%$ compliance (four trials), 0.80, 0.71 to 0.89 ). These results must be interpreted with caution as the four trials comprising the less than $50 \%$ category are from one study ${ }^{\mathrm{w} 27}$ and are compared with only one control group.

\section{Water supply and sanitation}

Subgroup analyses for each measure of effect were carried out according to whether the water supply or sanitation was "improved" or "unimproved" on the basis of established criteria. No statistically significant 


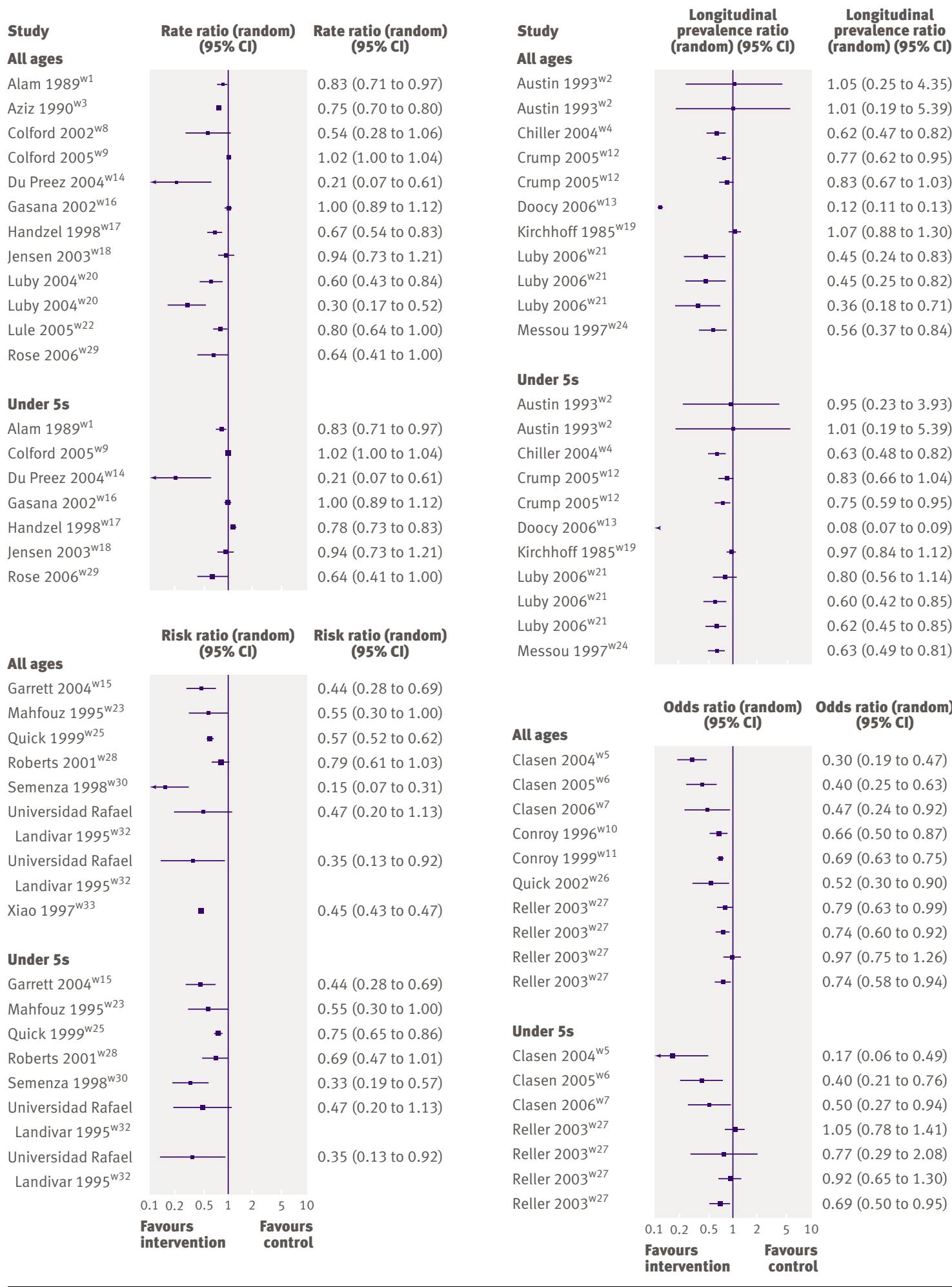

Fig 2 Forest plot of studies reporting rate ratios, risk ratios, longitudinal prevalence ratios, and odds ratios (random effects model). Squares are point estimates and horizontal lines are $95 \%$ confidence intervals. Size of square represents relative precision of trial results. Measures of effect less than 1 indicate reduced diarrhoea related morbidity with intervention

differences were found between pooled estimates on the basis of these criteria. However, pooled estimates show a statistically significant effect in favour of intervention even in settings without improved water supply (seven trials reporting rate ratios, $0.74,95 \%$ confidence interval 0.63 to 0.87 ; four trials reporting risk ratios, $0.46,0.36$ to 0.58 ; six trials reporting longitudinal prevalence ratios, $0.83,0.68$ to 1.01 ; and nine trials reporting odds ratios, $0.66,0.57$ to 0.77 ). Interventions were also effective in settings without 
improved sanitation (four trials reporting rate ratios, $0.78,0.64$ to 0.95 ; two trials reporting risk ratios, $0.55,0.47$ to 0.65$)$.

\section{Water quality only versus compound environmental interventions}

Pooled estimates showed that water quality interventions were significantly effective when introduced alone or in combination with other environmental interventions (hygiene instruction, improved water storage vessel, improved sanitation, or improved water supply). Notably, however, no evidence was found for water quality interventions being more effective when combined with other components than when implemented alone. Pooled estimates for water quality interventions alone (seven trials reporting odds ratios, $0.61,95 \%$ confidence interval 0.50 to 0.73 ; five trials reporting rate ratios, $0.76,0.52$ to 1.02 )

\begin{tabular}{|c|c|c|c|c|c|c|}
\hline \multirow[b]{2}{*}{ Study } & \multicolumn{4}{|c|}{ Randomised controlled trials* } & \multicolumn{2}{|c|}{$\begin{array}{l}\text { Quasirandomised controlled } \\
\text { trials }\end{array}$} \\
\hline & $\begin{array}{l}\text { Allocation } \\
\text { sequence } \dagger\end{array}$ & $\begin{array}{c}\text { Allocation } \\
\text { concealment }\end{array}$ & Blinding§ & $\begin{array}{l}\text { Losses to follow-up } \\
\text { in analysis }\end{array}$ & $\begin{array}{l}\text { Comparabil- } \\
\text { ity** }\end{array}$ & $\begin{array}{c}\text { Contemporaneity of } \\
\text { data collectiont† }\end{array}$ \\
\hline Alam $1989^{\text {w1 }}$ & - & - & - & - & Adequate & Adequate \\
\hline Austin $1993^{\mathrm{w} 2}$ & Adequate & Adequate & Open & Inadequate & - & - \\
\hline Aziz 1990w3 & - & - & - & - & Adequate & Adequate \\
\hline Chiller $2005^{\mathrm{w} 4}$ & Adequate & Adequate & Open & Adequate & - & - \\
\hline Clasen $2004^{\text {w5 }}$ & Adequate & Adequate & Open & Adequate & - & - \\
\hline Clasen 2006w6 & Adequate & Adequate & Open & Adequate & - & - \\
\hline Clasen $2005^{\mathrm{w} 7}$ & Adequate & Adequate & Open & Adequate & - & - \\
\hline Colford $2002^{\text {w8 }}$ & Adequate & Adequate & Blind & Adequate & - & - \\
\hline Colford $2005^{\mathrm{w} 9}$ & Adequate & Adequate & Blind & Adequate & - & - \\
\hline Conroy $1996^{\mathrm{w} 10}$ & Inadequate & Inadequate & Open & Adequate & - & - \\
\hline Conroy $1999^{w 11}$ & Inadequate & Inadequate & Open & Inadequate & - & - \\
\hline Crump $2005^{\mathrm{w} 12}$ & Unclear & Adequate & Open & Inadequate & - & - \\
\hline Doocy $2006^{\mathrm{w} 13}$ & Adequate & Adequate & Open & Adequate & - & - \\
\hline Du Preez $2004^{\text {w14 }}$ & Adequate & Adequate & Open & Adequate & - & - \\
\hline Garrett $2004^{\mathrm{w} 15}$ & - & - & - & - & Inadequate & Adequate \\
\hline Gasana $2002^{\text {w16 }}$ & - & - & - & - & Unclear & Unclear \\
\hline Handzel $1998^{\text {w17 }}$ & Unclear & Adequate & Open & Adequate & - & - \\
\hline Jensen $2003^{\text {w18 }}$ & & - & & & Inadequate & Adequate \\
\hline Kirchhoff $1985^{\text {w19 }}$ & Inadequate & Inadequate & Blind & Inadequate & - & - \\
\hline Luby $2004^{\text {w20 }}$ & - & - & - & - & Adequate & Adequate \\
\hline Luby $2006^{\text {w21 }}$ & Adequate & Adequate & Open & Adequate & - & - \\
\hline Lule $2005^{\text {w22 }}$ & Unclear & Adequate & Open & Adequate & - & - \\
\hline Mahfouz $1995^{\text {w23 }}$ & - & - & - & - & Adequate & Adequate \\
\hline Messou $1997^{\text {w24 }}$ & - & - & - & - & Adequate & Adequate \\
\hline Quick 1999w25 & Adequate & Adequate & Open & Adequate & - & - \\
\hline Quick 2002 $2^{\text {w26 }}$ & - & - & - & - & Adequate & Adequate \\
\hline Reller $2003^{\text {w27 }}$ & Adequate & Adequate & Open & Inadequate & - & - \\
\hline Roberts $2001^{\mathrm{w} 28}$ & Inadequate & Inadequate & Open & Inadequate & - & - \\
\hline Rose $2005^{\mathrm{w} 29}$ & Adequate & Adequate & Open & Adequate & - & - \\
\hline Semenza $1998^{\text {w30 }}$ & Adequate & Adequate & Open & Unclear & - & - \\
\hline Turon $1982^{\text {w31 }}$ & - & - & - & - & Adequate & Adequate \\
\hline $\begin{array}{l}\text { Universidad Rafael } \\
\text { Landivar } 1995^{\text {w32 }}\end{array}$ & Adequate & Adequate & Open & Unclear & - & - \\
\hline Xiao $1997^{\text {w33 }}$ & - & - & - & - & Adequate & Adequate \\
\hline \multicolumn{7}{|c|}{ 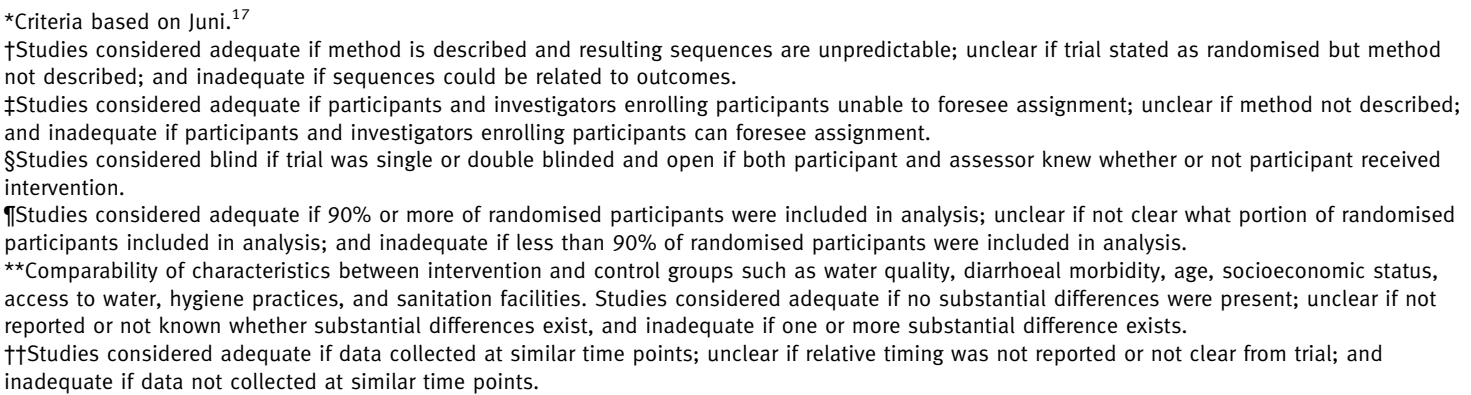 } \\
\hline
\end{tabular}


were not statistically different from pooled estimates for trials combining water quality with instruction on basic hygiene (one trial reporting odds ratio, $0.52,0.30$ to 0.90 ; three trials reporting rate ratios, $0.85,0.70$ to $1.03)$, water quality with a storage vessel (three trials reporting odds ratios, $0.77,0.58$ to 0.84 ; four trials reporting rate ratios, $0.61,0.46$ to 0.81 ), water quality plus sanitation (three trials reporting odds ratios, 0.60 , 0.43 to 0.84 ; one trial reporting rate ratio, $0.75,0.70$ to $0.80)$, or water quality with improved water supply (four trials reporting odds ratios, $0.70,0.59$ to 0.84 ; two trials reporting rate ratios, $0.77,0.71$ to 0.84 ).

\section{Study design; methodological quality}

Subgrouping trials on study design (randomised and quasirandomised controlled trials) did not show a trend in favour of either design approach (table 3). Greater protective effects were generally reported among randomised controlled trials with high quality for sequence generation, allocation concealment, and inclusion or losses to follow-up. Only four studies, however, used double blinding (table 1) and none of these found a statistically significant protective effect from the water quality intervention. Similarly, among quasirandomised controlled trials, effects in studies meeting the specified criteria for methodological quality were larger. Few trials, however, failed to meet these criteria, and subgroup analyses did not explain the heterogeneity.

\section{DISCUSSION}

This systematic review of 42 controlled trials among some 56000 participants shows that interventions to improve the microbial quality of drinking water are effective in reducing the occurrence of diarrhoea in adults and children. Although substantial heterogeneity was found in the magnitude of the effects, the evidence for the effectiveness of water quality interventions was compelling.

Pooled estimates from 12 studies reporting rate ratios suggest that household based interventions are more effective at preventing diarrhoea than water source based interventions. Such estimates, however, exclude the results from the two studies of source based interventions that reported the highest level of effectiveness and that achieved results equivalent to the household based interventions using the same measure of effect. ${ }^{\text {w24 w33 }}$ Evidence was also found for effectiveness being related to compliance with the intervention. Water quality interventions were effective in reducing diarrhoea even in the absence of improved water supplies and sanitation. Effectiveness did not seem to be enhanced by combining the intervention with other common strategies for preventing diarrhoea (instruction on basic hygiene, improved water storage, or improved water supplies and sanitation facilities). Although the evidence does not rule out additional benefit from combined interventions, it does raise questions about whether the additional cost of such integrated approaches as currently implemented is warranted on the basis of health gains alone.
Methodological strengths and weaknesses

The validity of the results of this systematic review depends on the validity of the included studies. Many of the trials were only quasirandomised and failed to take all the steps necessary to avoid bias. In subgroup analyses, however, trials that were of higher methodological quality for allocation concealment showed a greater overall level of effectiveness. Only four of the 22 randomised controlled studies, however, were properly blinded, and in each no statistically significant protective effect was found. ${ }^{\text {w2 }}$ w8 w9 w19 Two of the non-blinded trials were carried out in a developed country where drinking water already complied with US standards, ${ }^{\text {w8 w9 }}$ one trial included only 112 people (the smallest of all the included trials) and was rated low on three other criteria for methodological quality, ${ }^{\mathrm{w} 19}$ and one used dilute sodium hypochlorite in the control group, which may have improved water quality leading to an underestimate of the effectiveness of the study intervention. ${ }^{\text {w2 }}$ Thus other reasons apart from methodological concerns may exist for why these trials failed to show effectiveness. Nevertheless, in the light of the results from the non-blinded trials, some caution must be exercised in interpreting the strength of the evidence to date.

The design of the trials was not independent of the type of intervention. All seven trials concerning interventions at the water source were quasirandomised, whereas 31 of the 35 studies of point of use interventions were randomised. Although this reflects the difficulty of randomising users of water source interventions, our inferences about the relative effectiveness of these two approaches may be biased by the study design. Subgrouping on study design and meth odological quality did not suggest an association between effectiveness and method of randomisation. If the general observation that trials with weaker designs show more promising intervention effects applied to this population of studies, then the relative effectiveness of household and water source interventions may have been biased against household interventions.

Moreover, the context and length of follow-up in the trials was not independent of the intervention. Trials of household based interventions tended to be research driven investigations, whereas those of source based interventions were often evaluations of actual programmes. The duration of trials of source based interventions was nearly six times that of interventions at the household level. Four of the six trials on source based interventions lasted three or more years, whereas only four of the 35 household interventions lasted one year. Seasonality is important in assessing diarrhoea, and the failure to include data on diarrhoea for at least 12 months may have influenced the estimates of intervention of effect. ${ }^{21}$ Nevertheless, visual inspection of a scatter plot of trial duration against effectiveness showed no association.

The availability of water may be an important factor in the generalisability of these results. Interventions at the source are often designed primarily to improve 
water quantity and availability rather than quality. However, such improvements in water supply may be a separate and possibly more significant contributor to health than improvements in water quality. ${ }^{4}$ In the case of the household based interventions, most trials were carried out in settings with sufficient water, which may mean that these results cannot be generalised to locations where water supplies are inadequate. Our conclusions about source based interventions should not be interpreted to extend to household connections, which observational studies have found to be more effective in reducing diarrhoea. ${ }^{22}$

\section{Results in relation to other studies}

The most cited reviews of the effectiveness of interventions to prevent diarrhoea are by Esrey et al. ${ }^{89}$ These reviews, however, used a limited search strategy that omitted many studies, combined observational studies and trials, had limited assessments of methodological quality, and reported intervention effects as median reductions. The reviews included only studies investigating improvements of water quality at the source and did not include interventions at the household level. ${ }^{89}$ The $15 \%$ to $17 \%$ median reduction in occurrence of diarrhoea reported for source interventions is consistent with our results for source based interventions. Fewtrell et al ${ }^{14}$ reported significantly higher effectiveness from interventions at the household level (pooled estimates across different measures of effect of 35\% from 12 household based interventions compared with a statistically insignificant $11 \%$ from three source based interventions), but did not include several unpublished studies and included interventions against epidemic diarrhoea in their analysis, which could skew results.

\section{What the results mean}

Interventions to improve the microbial quality of water are effective in reducing the occurrence of endemic diarrhoea. Some evidence was found that household based interventions are capable of significantly higher levels of effectiveness, roughly comparable to certain other environmental interventions to prevent diarrhoea, such as improved sanitation, hygiene (hand washing with soap), and improved water supply. ${ }^{1423}$ Moreover, contrary to previous conclusions, ${ }^{2425}$ water quality interventions are effective even in the absence of improved sanitation and water supply and they do not always require concomitant hygiene promotion for their effectiveness. These results support the WHO strategy of promoting the treatment and safe storage of household water as a means of accelerating the health gains of safe drinking water, even though it may not reduce the numbers of people $(1.1$ billion) currently without access to improved water supplies.

\section{Unanswered questions and future research}

Rigorous, multiarm randomised controlled trials in different settings that compare various approaches to improving drinking water quality will help clarify the potential for water quality interventions to prevent endemic diarrhoea. It is particularly important that such trials be blinded, if possible, not only for the methodological reasons that favour blinded trials generally but also because of the ineffectiveness reported in blinded studies of water quality interventions to date. A need also exists for longer term studies in programmatic (non-research driven) settings, especially on household based interventions. Differences in programmatic approaches to optimise the adoption and long term utilisation of these interventions should also be investigated. Finally, as most of the burden from diarrhoeal disease is associated with mortality rather than with morbidity, future research should include studies specifically designed to determine the effectiveness of interventions to improve water quality in preventing death, particularly among vulnerable populations such as the under $5 \mathrm{~s}$ and people living with HIV/AIDS

Household interventions require effort on the part of householders to treat their water correctly, to have treated water consistently available, to avoid recontamination, and to refrain from drinking from untreated sources. Each of these conditions creates an opportunity for non-compliance, which we found to reduce effectiveness. Most source based interventions, however, extended to the household's entire water supply without any additional steps for compliance on the part of the intervention population. It is therefore important to assess whether the target population will use these household interventions correctly and consistently over the long term.

Ultimately the value of water quality interventions in preventing diarrhoeal disease depends not only on their effectiveness but also on their affordability, acceptability, sustainability, and scalability within a vulnerable population-issues that the studies included in this review mainly did not address. Comprehensive cost effectiveness and cost benefit analyses will also help establish the priority that should be attached to water quality interventions by the public sector, donors, and non-governmental organisations.

We thank Greg Allgood, Jamie Bartram, Julia Bohlius, Joseph Brown, Jack Colford, John Crump, Tom Chiller, Val Curtis, Shannon Doocy, Lorna Fewtrell, Carrol Gamble, Bruce Gordon, Stephen Gundry, Bruce Keswick, Steve Luby, Rob Quick, Mark Sobsey, Sara Thomas, and James Wright for their research, advice, assistance, and other valuable contributions; members of the Cochrane Infectious Diseases Review Group; and the referees of the Cochrane review and its protocol. This is an updated and vastly abbreviated version of the Cochrane review. The authors agreed to change the order of authorship on this paper to reflect their contributions to this paper compared with the full review.

Contributors: SC conceived the review. TC coordinated the review, drafted the protocol and review, carried out the search strategy, retrieved the papers, contacted authors, and prepared the tables and figures. TC is guarantor. TC, IR, TR, and W-PS designed the review. TC and TR screened the search results. TC, TR, and SC applied the inclusion criteria. TC, TR, and W-PS extracted the data, calculated estimates of effect, and dealt with the statistics. TC, TR, and IR applied the quality criteria. TC and W-PS entered data into RevMan. IR, TR, WPS, and SC commented on the review.

Funding: None. 


\section{WHAT IS ALREADY KNOWN ON THIS TOPIC}

Water that is safe at the point of collection often becomes contaminated with faeces during transport, use, and storage in the home

\section{WHAT THIS STUDY ADDS}

Interventions to improve the microbial quality of water are effective for preventing diarrhoea The interventions were effective in people of all ages and in under $5 \mathrm{~s}$

Competing interests: TC, W-PS, and SC participate in research supported by Unilever and Vestergaard-Frandsen, which manufacture and sell household or other point of use water treatment devices.

Ethical approval: Not required.

1 World Health Organization. The world health report: 2005: make every mother and child count. Geneva: WHO, 2005.

2 World Health Organization. Progress towards the Millennium development goals, 1990-2005. (http://unstats/un.org/unsd/mi/ goals_2005/goal_4.pdf) (accessed 15 Nov 2005).

3 World Health Organization and United Nations Children's Fund. Global water supply and sanitation assessment. Geneva: WHO/ UNICEF, 2000.

4 Cairncross S. Water supply and sanitation: an agenda for research. Trop Med Hyg 1989;92:301-14.

5 Esrey SA, Habicht J-P. Epidemiologic evidence for health benefits from improved water and sanitation in developing countries. Epidemiol Rev 1986;8:117-28.

6 Lindskog U, Lindskog P, Wall S. Water supply, sanitation and health education programmes in developing countries: problems of evaluation. Scand J Soc Med 1987;15:123-30.

7 Briscoe J. Intervention studies and the definition of dominant transmission routes. Am / Epidemiol 1984;120(3):449-55.

8 Roy S, Scallan E, Beach MJ. The rate of acute gastrointestinal illness in developed countries. J Wat Health 2006;4(Suppl 2):31-70.

9 Colford JM, Roy S, Beach MJ, Hightower A, Shaw SE, Wade TJ. A review of household drinking water intervention trials and an approach to the estimation of endemic waterborne gastroenteritis in the United States. J Wat Health 2006;4(Suppl 2):71-88.

10 Esrey SA, Feachem RG, Hughes IM. Interventions for the control of diarrhoeal diseases among young children: improving water supplies and excreta disposal facilities. Bull WHO 1985;64:776-2.

11 Esrey SA, Potash JB, Roberts L, Shiff C. Effects of improved wate supply and sanitation on ascariasis, diarrhoea, dracunculiasis, hookworm infection, schistosomiasis, and trachoma. Bull WHO 1991;69:609-21.

12 Sobsey MD. Managing water in the home: accelerated health gains from improved water supply. Geneva: WHO, 2002. (WHO/SDE/ WSH/02.07.)

13 Clasen T, Cairncross S. Household water management: refining the dominant paradigm. Trop Med Int Health 2004;9:1-5

14 Fewtrell L, Kaufmann R, Kay D, Enanoria W, Haller L, Colford J. Water, sanitation, and hygiene interventions to reduce diarrhoea in less developed countries: a systematic review and meta-analysis. Lancet Infect Dis 2005;5:42-52.

15 Wright J, Gundry S, Conroy R. Household drinking water in developing countries: a systematic review of microbiological contamination between source and point-of-use. Trop Med Int Health 2003;9:106-17.

16 Clasen T, Roberts I, Rabie T, Schmidt W, Cairncross S. Intervention to improve water quality for preventing diarrhoea. Cochrane Database Syst Rev 2006;(3):CD004794.

17 Juni $P$, Altman DG, Egger M. Systematic reviews in health care: assessing the quality of controlled trials. BMJ 2001;323:42-6.

18 Higgins JPT, Green S, eds. Analysing and presenting results. Cochrane handbook for systematic reviews of interventions 4.2.5 [updated May 2005]; appendix 5b. www.cochrane.org/resources/ handbook/hbook.htm (accessed 1 Jan 2006).

19 Egger M, Smith GD, Altman DG, eds. Systematic reviews in health care: meta-analysis in context. London: BMJ Books, 2001.

20 Higgins JPT, Thompson SG, Deeks JJ, Altman DG. Measuring inconsistency in meta-analysis. BMJ 2003;327:557-60.

21 Blum D, Feachem RG. Measuring the impact of water supply and sanitation investments on diarrhoeal diseases: problems in methodology. Int J Epidemiol 1983;12(3):357-65.

22 Cairncross S, Valdmanis V. Water supply, sanitation, and hygiene promotion. In: Jamison DT, Breman JG, Measham AR, Alleyne G, Claeson M, Evans DB, et al, eds. Disease control priorities in developing countries. 2nd ed. New York: Oxford University Press, 2006

23 Curtis V, Cairncross S. Effect of washing hands with soap on diarrhoea risk in the community: a systematic review. Lancet Infect Dis 2003;3:275-81.

24 Briscoe J, Feachem RG, Rahaman MM. Evaluating health impact: water supply, sanitation, and hygiene education. Ottawa: International Development Research Centre, 1986.

25 Van Derslice J, Briscoe J. Environmental interventions in developing countries: interactions and their implications. Am J Epidemiol 1995;41:135-44.

Accepted: 4 January 2007 